\title{
“BATUCA LÁ, QUE EU BATUCO CÁ”: OS TERREIROS DE UMBANDA E SUAS CONJUNTURAS SOCIAIS
}

\author{
"GOLPEA EL TAMBOR AHÍ, QUE LO GOLPEO ACÁ": LOS TERREIROS \\ DE UMBANDA Y SUS CONJUNCIONES SOCIALES
"YOU HIT THE DRUM THERE, I HIT THE DRUM HERE”: UMBANDA MEETING PLACES AND THEIR SOCIAL CONJUNCTURES

\section{Matheus Barbosa da Rocha ${ }^{1,}$ Ana Kalliny de Sousa Severo² e Antônio Vladimir Félix-Silva ${ }^{3}$}

${ }^{1}$ Universidade Federal do Piauí, Teresina/PI, Brasil

${ }^{2}$ Universidade Federal do Rio Grande do Norte, Natal/RN, Brasil

${ }^{3}$ Universidade Federal do Piauí, Teresina/PI, Brasil

\begin{abstract}
RESUMO: As religiões afro-brasileiras surgiram quando milhares de africanos foram trazidos das suas terras natais para o Brasil com o intuito de terem suas forças de trabalho, bem como a si próprios, transformados em mercadorias. Este artigo traz como campo de problematização as tessituras dialógicas das religiões de terreiros com o contexto social, econômico e político nas quais elas estão inseridas. Metodologicamente, nos filiamos ao referencial da Análise Institucional "no Papel”. Os sujeitos foram três líderes de terreiros e os respectivos praticantes/consulentes dos estabelecimentos religiosos que os mesmos conduziam. No cenário urbano, podemos afirmar que situações de violência circundam os sujeitos devotos de tais religiões, os quais têm ocupado zonas historicamente impossibilitadas do acesso à saúde, educação, assistência, segurança, moradia, transporte público de qualidade e infraestrutura urbana. Tais situações operam no nível do instituído, produzindo, muitas vezes, reverberações nos modos de ser e de existir dos adeptos e consulentes dessas crenças.
\end{abstract}

PALAVRAS-CHAVE: Religião; Discriminação social; Iniquidade social.

RESUMEN: Las religiones afrobrasileñas surgieron cuando miles de africanos fueron traídos de sus tierras natales a Brasil con el propósito de tener sus fuerzas de trabajo, así como a sí mismos, transformados en mercancías. Este artículo objetivó investigar las tesituras dialógicas de las religiones de terreiros con el contexto social, económico y político en las que ellas están insertadas. Como método, utilizamos el referencial del Análisis Institucional "en el Papel”. Los participantes del estudio fueron tres líderes de terreiros y los respectivos practicantes/consultantes de los establecimientos religiosos que ellos mismos conducían. En el escenario urbano, podemos afirmar que situaciones de violencia circundan a los sujetos devotos de esas religiones, los cuales han ocupado zonas históricamente imposibilitadas del acceso a la salud, educación, asistencia, seguridad, vivienda, transporte público de calidad e infraestructura urbana. Estas situaciones operan a nivel de lo instituido, produciendo, muchas veces, reverberaciones en los modos de ser y de existir de los adeptos y consultantes de esas creencias.

PALABRAS CLAVE: Religión; Discriminación social; Inequidad social.

ABSTRACT: The african-Brazilian religions arose when thousands of Africans were brought from Africa to Brazil in order to have their workforces and themselves become commodities. This article presents as a field of problematization the interfaces between the religions of terreiros and the social, economic and political context in which they are inserted. As a working method, we use Institutional Analysis "on paper". The participants were three leaders of terreiros (Umbanda meeting places) and the respective practitioners/consultants of the religious spaces that they led. In the urban scenario, we can affirm that situations of violence are present in the daily life of the faithful of such religions. These people have occupied areas historically deprived of access to health, education, assistance, security, housing, high quality public transport and urban infrastructure. These cases operate at the level of the instituted, often producing consequences in the subjectivities of the faithful and consultants of these religions.

KEYWORDS: Religion; Social Discrimination; Social Inequity. 


\section{Introdução}

Este artigo, recorte de uma pesquisa de mestrado intitulada "Nos Batuques dos Quintais: As Interfaces do Cuidado em Saúde entre Religiões de Terreiros e Equipes de Saúde da Família (ESF)", traz como campo de problematização as tessituras dialógicas entre as religiões de terreiros e o contexto social, econômico e político em que as mesmas estão inseridas.

Um primeiro aspecto importante de trazermos às problematizações diz respeito ao fato de que o continente africano, anterior ao século XV, era composto por diversas nações ou tribos, cada uma com suas próprias etnias, costumes, crenças e tecnologias. Com a chegada dos portugueses na região, estes terminaram por se aproveitar do modo de organização tribal instituído pela população nativa, objetivando incentivar guerras entre as diferentes nações. Os vencidos eram colocados à venda ou trocados com os europeus por produtos necessários e apreciados pelos africanos, como sal e cachaça (Barros, 2009).

Com essa artimanha, os portugueses pretendiam utilizar o trabalho destes povos como mão de obra escravizada nas usinas de cana de açúcar do Nordeste brasileiro. Posteriormente, com o passar dos séculos, também vieram a instituir o trabalho de tais sujeitos tanto nos garimpos de ouro de Minas Gerais quanto nas lavouras de café, localizadas nos interiores de São Paulo e Rio de Janeiro. Para chegar ao Brasil, esses povos eram exportados aos montes em navios cargueiros, conhecidos por possuírem insalubres condições para se viver, o que culminava em uma dizimação dos negros já durante a viagem.

Ao chegarem ao Brasil, os negros se depararam com uma sociedade instituída pelo teor aristocrata e escravista, atribuindo àqueles oriundos da África um valor mercadológico de compra e venda, assim como qualquer outro produto. Para legitimar seu poder, tal sistema fazia uso da coerção, bem como da violência física, psicológica e de diversos outros tipos de humilhações (Castro, 2012).

Nessa relação colonizadora, não demorou muito para que os portugueses percebessem que os africanos não cultuavam ao mesmo Deus e santos católicos. Por conta disso, a responsabilidade pela "educação religiosa" dessas pessoas ficou sob tutela dos "senhores

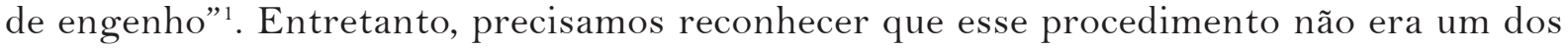
mais exigentes, já que o intuito principal era explorar ao máximo a força de trabalho dos negros (Castillo, 2017).

Em decorrência deste e de outros fatores, os sujeitos escravizados organizaram uma série de movimentos instituintes contra essa dominação, como fugas, boicotes ao trabalho, organizações de quilombos e preservação dos seus principais elementos culturais, tais como dialetos, cantigas, danças, religiões e práticas de cura e cuidado em saúde. Contudo, estes atos passaram a se instituir de modo camuflado, como, por exemplo, as divindades africanas travestidas de santos católicos (Freitas, 2012).

Além disso, a ineficiência e o descaso dos tratamentos médicos durante o governo imperial também foram elementos definidores no deslocamento das religiões de matrizes africanas no cenário brasileiro. Nesse sentido, quando estavam diante de situações de adoecimento, os sujeitos recorriam às suas crenças religiosas, buscando apoio nos Orixás africanos, nos espíritos antepassados, nos rituais de possessão e no uso de amuletos e plantas medicinais (Lages, 2012). 
Tais estabelecimentos religiosos promotores de cuidado em saúde historicamente têm sido circunscritos por conjunturas sociais, econômicas e políticas, sendo, portanto, extremamente necessária a realização de investigações que se detenham em análise sobre o referido processo. No interior dessa problemática, algumas questões têm ganhado o interesse dos pesquisadores nos últimos anos, tais como: as situações de preconceito, discriminação e intolerância direcionadas aos povos de terreiros (Campos \& Rubert, 2014; Pereira, 2017; Rocha, 2011); as relações das religiões de matrizes africanas, tanto com o movimento negro, (Lima \& Mariano, 2008), quanto também com a cidade (Sales, 2014).

Entretanto, no campo da Psicologia Social, ainda são escassos os estudos que problematizam as conjunturas sociais, econômicas e políticas relacionadas aos praticantes e consulentes das doutrinas religiosas afro-brasileiras, o que justifica a realização do referido trabalho, principalmente em decorrência do mesmo ter sido realizado em uma cidade da região da planície litorânea do estado do Piauí, cenário no qual tais investigações sobre a referida temática ainda são praticamente inexistentes.

Diante de um cenário que frequentemente promove uma "geografia do terror" a determinados segmentos sociais, como os povos de terreiros, é de se esperar que a Psicologia Social, com seu compromisso ético-político, dialogue com essas problemáticas sociais.

\section{Percurso metodológico}

Como matriz de investigação e como estratégia de produção e análise das informações, adotamos o referencial da Análise Institucional, de René Lourau e Georges Lapassade, mais especificamente em uma perspectiva denominada como "no Papel”, caracterizada como um método de conhecimento e de práticas em que se objetiva realizar uma análise econômica, política, funcional, estrutural e estruturo-funcional dos processos sociais que nos circundam, sendo utilizada tanto em pesquisas teóricas quanto de campo, por possibilitar uma ampla análise dos processos institucionais (Lourau, 1995). Nessas modalidades de pesquisa, um conceito demasiadamente importante é o de analisador, compreendido como aquilo que nos permite provocar os conteúdos outrora implícitos das instituições, fazendo-os ver e falar (Lourau, 2004).

Para alcançarmos o objetivo da pesquisa, utilizamos os seguintes instrumentais: entrevistas semi-estruturadas com três líderes de terreiros de Umbanda (Ashanti, Mmaabo e Azekel) ${ }^{2}$; observação participante das cerimônias religiosas em que as casas espirituais conduzidas por esses sujeitos ofertavam espaços de cura, cuidado em saúde, aconselhamento e orientação espiritual à população de forma geral; e conversas informais com os praticantes e consulentes dos respectivos estabelecimentos sagrados. A construção desse grupo estudado ressalta a importância atribuída à ancestralidade e à hierarquia, comum entre esses povos e também a muitas populações nativas brasileiras.

A pesquisa foi conduzida em uma cidade do litoral piauiense. A mesma possui aproximadamente 150 mil habitantes, e se localiza a aproximadamente $340 \mathrm{~km}$ da capital. Apesar disso, esse município historicamente foi vítima tanto dos poucos investimentos em infraestrutura urbana, quanto também da inexistência de uma rede de transportes públicos de qualidade. Além disso, é preciso ressaltar que a mesma é caracterizada por um acentuado conservadorismo religioso que permeia os seus habitantes. No ano de 2010, a maior parte 
da população se autodenominava pertencente à religião católica apostólica romana, seguida das religiões evangélicas. Além disso, também é válido ressaltar que considerando domicílios com rendimentos mensais de até meio salário mínimo por pessoa, $45.1 \%$ da população encontravam-se nessas condições, o que o colocava na posição 219 de 224 dentre as cidades do estado (IBGE, 2010).

Tabela I - Atendimentos em Saúde nos Terreiros Investigados

\begin{tabular}{|c|c|c|}
\hline Terreiros & Dias e Horários de Funcionamento & Imersão \\
\hline Ashanti & $\begin{array}{c}\text { Consulente é atendido a qualquer momento } \\
\text { que chegue. }\end{array}$ & $\begin{array}{c}\text { Não acompanhamos os } \\
\text { atendimentos }\end{array}$ \\
\hline Mmaabo & Três vezes por semana & Oito Visitas \\
\hline Azekel & Uma vez por semana (três vezes por mês). & Três Visitas \\
\hline
\end{tabular}

Duas das casas espirituais investigadas eram conduzidas por mulheres (Ashanti e Mmaabo). Ambas eram negras, tinham aproximadamente 60 anos de idade e realizavam suas atividades espirituais em salões construídos nos quintais das suas próprias residências. Ao contrário delas, o terceiro centro religioso era conduzido por um homem de aproximadamente 45 anos de idade (Azekel) e possuía como característica principal o fato de funcionar em um espaço alugado exclusivamente reservado para essa função.

De modo geral, as regiões em que os referidos terreiros estavam situados guardavam algumas semelhanças entre si. A primeira diz respeito ao fato de estarem localizadas em regiões consideradas "antigas" da cidade: enquanto dois dos bairros tiveram suas origens nos arredores de um leprosário, o outro surgiu em virtude de um programa de distribuição de casas populares realizado pelo então governador do Estado.

Além disso, outras características apresentadas pelas regiões em que estavam localizados os estabelecimentos religiosos são: altos níveis de violência urbana; péssimas condições de infraestrutura, tais como calçamentos quebrados, algumas ruas de areia e uma ínfima quantidade de postes com iluminação noturna; e dificuldade no acesso a essas regiões, principalmente em virtude dos poucos transportes públicos que fazem rotas até os respectivos bairros, problema este que se confunde com uma situação crônica que atravessa a própria cidade em estudo ${ }^{3}$.

\section{Conjunturas sócio-econômico-políticas das populações de terreiros}

No decorrer da história, o que hoje conhecemos como tempo e espaço físico foram objetos de inúmeras compartimentações, sendo definidos principalmente pela lentidão e rigidez que lhe caracterizavam (Santos, 2006). No cenário contemporâneo, vivemos um mundo em que há uma apropriação de novos sistemas técnicos e de informação a fim de obter uma fluidez e velocidade virtual na realização das atividades cotidianas, que apesar de supostamente se apresentarem como acessíveis a todas as pessoas, estabelecimentos e organizações, apenas algumas têm a possibilidade de utilizá-las e se tornarem detentoras efetivas dessa fluidez e velocidade, como é o caso das empresas e demais estabelecimentos do setor da economia (Santos, 1988). 
Diante desse cenário atual, assistimos a um duplo processo de funcionamento da sociedade: as verticalidades e as horizontalidades. No primeiro caso, há uma extrema hierarquização dos atores sociais e econômicos, havendo um forte apelo para o setor relacionado ao âmbito informacional e técnico-científico. Por outro lado, no que se refere às horizontalidades, estas são concebidas em torno de "um cotidiano compartilhado entre as mais diversas pessoas, firmas e instituições” (Alves \& Paula, 2014, p. 2323).

É possível, portanto, identificar arranjos de luminosidade e opacidade que gravitam em torno das horizontalidades e das verticalidades. Nos arranjos de luminosidade, o subsistema hegemônico da economia impera, produzindo reverberações nos sistemas sociais e culturais, de modo a agir sobre o restante não hegemônico da sociedade. É um cenário em que opera a lógica da globalização (Santos, 2013).

Em oposição, existem determinadas zonas que não funcionam em conformidade com essas leis: suas infraestruturas são incompletas e herdadas do passado; há um predomínio da economia não reinante, o que abre espaço para a flexibilidade e, portanto, a todos os tipos de trabalhos; e, por fim, são nessas instâncias que as classes sociais marginalizadas encontram possibilidades de sobreviver (Santos, 2007).

Todavia, não devemos pensar nas horizontalidades/verticalidades como processos dialéticos, em que os territórios funcionariam supostamente ou, por um lado, sob a égide de uma ordem social imposta pelos atores hegemônicos e, em consequência, obedecida desenfreadamente pelos sujeitos subalternizados, ou que, num outro extremo, se desenharia através de atividades políticas caracterizadas única e exclusivamente por encontros, desencontros, debates e acordos, cujo intuito final seria a produção de novas formas da existência.

Antes disso, acreditamos no caráter concomitante entre os dois processos: tanto conseguimos imaginar cenários em que o movimento determinante é o da racionalidade pragmática enquanto a produção de espaços marginais é residual, como também é possível perceber situações em que a lógica do dinheiro e do lucro não seja a dominante, mas sim as relacionadas às estéticas da existência e à realização plena da vida.

Por isso, assim como atesta o geógrafo Milton Santos, também apostamos na esquizofrenia dos territórios, visto que, se por um lado acreditamos que tais espaços físicos e subjetivos acolhem os vetores da globalização, responsáveis por instalar uma nova ordem social, por outro lado, também conseguimos presenciar a emergência e explosão de uma contra ordem em que produz desenfreadamente indivíduos em condições marginais de existência (Santos, 2006).

Tais afirmações talvez nos esclareçam melhor o caráter esquizofrênico do território que adentramos. Num primeiro plano, poderíamos, erroneamente associá-lo tão somente com a opacidade, já que os três centros religiosos investigados estão localizados em regiões carentes de infraestrutura urbana de qualidade, tais como considerável distância entre os estabelecimentos de sacralidade e os principais pontos comerciais e financeiros da cidade e a carência de transportes públicos circulando em dias e horários regulares, bem como em quantidade suficiente, quando comparamos com outros bairros nos quais havia movimentação urbana relativamente maior.

No entanto, apesar desses estabelecimentos estarem localizados em zonas distantes dos "centros econômicos", as pessoas que o frequentavam não compartilhavam territórios e modos de vida semelhantes, em vez disso, habitavam os mais variados espaços do muni- 
cípio e suas regiões vizinhas, chegando a transitar entre a luminosidade e a opacidade. O que não caracterizaria por completo nem as horizontalidades nem as verticalidades.

Tais aspectos, em maior ou menor medida, fazem menção ao que o educador Paulo Freire concebe como sendo "cidadania", compreendida, de acordo com o autor, como um fenômeno social muito mais complexo do que simplesmente considerar uma pessoa como originária de uma determinada localidade. Em vez disso, trata-se muito mais de concebermos tal conceito como uma construção política, em que os interesses de determinados sujeitos estariam em jogo (Freire, 2004). Trata-se de uma verdadeira construção de força dessas territorialidades, se aproximarmos Freire e Milton Santos.

Desse modo, também consideramos como cidadãos dos territórios investigados as pessoas que, por exemplo, moravam em outros bairros da cidade ou em municípios vizinhos e que semanalmente iam aos terreiros, compartilhando, com os demais fiéis e consulentes, doutrinas, afetos, desejos e um vínculo com o território que elas costumeiramente habitavam, mas não residiam.

Nesse sentido, atestamos que os terreiros em comunidades tradicionais não têm a mesma função e simbologia que nos espaços urbanos. Em uma comunidade quilombola, eles são frequentados majoritariamente por aqueles que moram nas redondezas, o que culmina com que os adeptos de fato não compartilharem apenas uma religião, mas também muitas das tradições familiares e comunitárias. Entretanto, no âmbito das cidades, esse fenômeno se desenrola através de outros meios, já que, nesse caso, um terreiro de Umbanda estar localizado em uma dada região não necessariamente significa que seus adeptos e consulentes também serão de lá.

Desse modo, no contexto dos três terreiros investigados, os seus adeptos e consulentes não habitavam as redondezas dos terreiros, como poderíamos erroneamente supor, mas, em vez disso, eram das mais distintas localidades da região litorânea do estado (composta por quatro municípios).

Durante nosso mergulho nos territórios em estudo, uma situação que chamou nossa atenção foi a de que nos centros religiosos conduzidos por Mmaabo e por Azekel, os consulentes costumavam chegar com muitas horas de antecedência para serem atendidos primeiro e, assim, poderem ir embora mais cedo, já que, segundo os próprios, o transporte público municipal era algo extremamente debilitado, principalmente no período da noite e nos finais de semana, momentos nos quais costumeiramente acontecem os rituais umbandistas do município.

Podemos, portanto, perceber que passam a ser frequentes as circunstâncias de uma pessoa morar em uma região, frequentar um terreiro em outra, ir ocasionalmente para um igreja católica ou evangélica em uma terceira localidade e não necessariamente ter sido criada nas tradições afro-brasileiras, e/ou ter desenvolvido sua mediunidade e participado de rituais religiosos específicos a essas crenças.

No que se refere aos desenhos que essas religiões afro-brasileiras adotam no cenário das cidades, um primeiro aspecto importante a se destacar diz respeito ao fato de que enquanto os terreiros de Ashanti e Mmaabo funcionavam onde as respectivas mães de santo moravam, o centro conduzido por Azekel realizava suas cerimônias espirituais em uma moradia alugada exclusivamente para esse fim.

Nesse cenário, um analisador cuja problematização é necessária no que se refere às tessituras dialógicas entre as crenças afro-brasileiras, mais especificamente a Umbanda, 
e o contexto social em que elas se encontram inclusas, diz respeito a como a sociedade de forma geral percebe e age diante dessas doutrinas e, além disso, quais reverberações tais práticas produzem nos modos de ser e de existir dos atores (líderes, adeptos e consulentes) que compõem esses estabelecimentos religiosos.

Sobre esse assunto, em nossos cenários de pesquisa, algumas figuras-chave relataram relações pacíficas e, em determinados casos, até mesmo exitosas, com a população em geral, em decorrência das religiões que professavam. De modo geral, conseguimos identificar essas questões tanto nos discursos de Ashanti e Mmaabo quanto também em alguns dos consulentes dessa figura-chave. Nesse último caso, alguns deles relataram não sofrer qualquer espécie de discriminação pelo fato de acompanharem as atividades do terreiro em questão.

Entretanto, precisamos ressaltar que o fato de tais sujeitos pertencentes ao terreiro de Mmaabo serem apenas consulentes, e não filhos de santo ou outra espécie de praticante, poderia ser um aspecto que nos possibilitaria compreender com mais nitidez esse suposto processo de aceitação social: de certo modo, essas pessoas, em tais circunstâncias, não vivenciavam os terreiros em suas completudes, não participando, portanto, de todas as atividades por eles ofertadas.

Ao contrário desses discursos, Mmaabo informou que quando se mudou para a casa onde residia no momento da realização da pesquisa, os vizinhos não a aceitavam por conta da sua religião, a Umbanda. Apenas com o decorrer dos anos, esses sujeitos foram se acostumando com suas doutrinas, vestimentas, batuques nos tambores e assim por diante. Além disso, ela também narrou possuir uma convivência harmônica com a Igreja Católica:

Mmaabo: minhas netas também tinha cerimônia, mas agora elas não tem mais, né? Elas não tem mais. [...]. Elas vão pro terreiro e tudo. E ai tamo levando, né? E aqui... meus vizinhos aqui tudo são legais. [...]. De primeiro, eles era, assim, um pouco disconfiados, né? Mas, agora, graças a Deus, como eles já viram... Eu quando ia pruma parte. Eu num saía daqui fardada, nem meus médiuns, chega lá que nós fardava, agora, nós já sai daqui todo mundo fardado em tudo e eles fica assistindo e tudo. Eu faço as festas de Iemanjá, ai vem um bocado de gente aí, faço a festa de rei Sebastião e eles vêm, toca no tambor, toca de tudo. Eles não tem receio comigo, são meus amigos. Até agora... Não sei mais pra frente, porque agora eles são meus amigos.

Outra líder religiosa que também trouxe discursos semelhantes aos anteriormente supracitados foi Ashanti. Ela nos informou que as pessoas costumavam respeitá-la, visto que, por mais que os mesmos tivessem preconceito com a Umbanda, estes também sabiam dos conhecimentos que a mesma possuía sobre religiões e sobre o cuidado em saúde. Como ilustração, Ashanti nos contou sobre uma conversa que ela teve com um pastor de uma igreja protestante.

Segundo a própria, o seu diálogo com a distinta figura passeou por várias questões relacionadas à religiosidade. Em determinado momento, nossa protagonista questionou o pastor sobre a função dele na igreja. Entretanto, ele começou a se esquivar da resposta. Depois de perceber que o seu convidado não responderia a pergunta, Ashanti finalmente afirmou que a função de um pastor é ser um pai. Ela prosseguiu dizendo que o mesmo acontecia no seu terreiro: ela agia como mãe. Após esse diálogo, segundo a própria, o re- 
ferido homem saiu de lá extremamente impressionado com os conhecimentos da mulher com quem conversara.

O reconhecimento dos saberes e experiências de Ashanti extrapola a comunidade em que ela está inserida e, em muitas situações, consegue se expandir em direção a outros lugares, sejam eles próximos ou longínquos. No contex to da cidade em estudo, o trabalho de Ashanti é bastante valorizado. Pessoas das mais distintas escolaridades e estratos sociais a procuram por vários motivos, sejam eles para cura de queixas físicas ou espirituais, auxílio no âmago da existência (tais como términos de namoro ou desemprego), realização de partos, aconselhamento, dentre outros trabalhos.

A partir desses discursos trazidos por Ashanti e Mmaabo, pudemos perceber que a convivência entre os estabelecimentos sagrados afro-brasileiros, mais especificamente a Umbanda, com a sociedade de forma geral, nem sempre é um processo harmônico e pacífico. Ambas nos relataram histórias de menosprezo por parte de suas respectivas famílias em decorrência das crenças que professavam e da mediunidade que desde cedo nelas se desenvolvia.

Ashanti: eu passei por essas provações de família, que não gostava de mim porque eu era diferente dos outros irmãos: "por que os seus outros irmãos não é assim?"; “por que só você é desse jeito?”; por que só você nasceu assim?”. Entendeu? Então, tinha aquele preconceito: o preconceito da família.

Mmaabo: eu sofri demais pra mim chegar a esse dom. Minha mãe não queria, meu pai não queria, nós somos do Maranhão, eu não sou daqui mesmo, né? Até que minha mãe aceitou, meu pai também aceitou, porque lá no Maranhão disseram pra ela [que] se eu não me aceitar, a sina que eu tinha trazido de nascença: [tanto] eu ia durar pouco quanto ia ficar louca, aí até que ela melhorou. Aí até hoje eu já tô melhor.

A partir desses discursos, é possível apreender um fato de extrema importância para nossas problematizações: os constantes casos de preconceitos, discriminações e intolerâncias contra os povos de terreiros são produzidos e reproduzidos pelos próprios familiares, sejam eles pais, mães, tios, tias, avôs ou avós, ao afirmarem que não vão aceitar determinado parente "por ele ser da macumba e bater o tambor".

De modo geral, essa realidade assim decorre em virtude de que com o surgimento da família canônica na década de 1830, todos os "desvios" do modelo economicamente produtivo, biologicamente reprodutor e teologicamente temente a Deus e a Jesus Cristo passaram a ser classificados como aberrações (Miskolci, 2003). Assim, não é de se espantar que muitas das práticas populares dos sujeitos escravizados e remanescentes de comunidades tradicionais passaram a ser mal-vistas, sendo socialmente consideradas, em muitos casos, como crimes e pecados, como a Capoeira e o Candomblé.

Isso não significa, todavia, que essas situações de descaso às africanidades estejam restritas aos recônditos mais íntimos do lar. Pelo contrário. Elas se intensificam, se bifurcam e se capilarizam nos mais distintos cenários, adquirindo contornos explícitos ou sutis, conforme o contexto social assim exija. Por exemplo, Azekel, juntamente com algumas adeptas do centro religioso que ele fazia parte, confessaram constantemente serem menosprezados de forma velada, nos momentos em que afirmavam serem praticantes de uma religião de base africana. 
Logo, nem todos os sujeitos são merecedores do mesmo modo de terem suas vidas perpetuadas: algumas etnias simplesmente passam a ser consideradas superiores, enquanto outras, não. E isso não acontece por acaso, o que visualizamos nesse cenário é a criação de querelas étnicas como estratégias de poder e de conformação dos corpos e das subjetividades (Foucault, 2005).

Como ilustração de circunstâncias de menosprezo, preconceito e discriminação contra os povos de terreiros, mencionamos os discursos de Ashanti e Mmaabo. No primeiro caso, com exceção dos jovens da comunidade, sujeitos que já eram alvo dos projetos sociais desenvolvidos pela figura-chave em questão, a maioria das pessoas do seu bairro a enxergava como uma bruxa enviada pelo demônio. Relatos semelhantes também foram proferidos por Mmaabo, contudo, em seu caso, segundo a própria, esses tipos de situações haviam se abrandado à medida que os seus vizinhos passaram a conhecê-la melhor:

Mmaabo: no começo, as pessoas quando me viam, aí ficavam, não dizia nada, mas a gente notava que, né? Aí, às vezes, eu passava por um que dizia: "essa mulher é macumbeira”. Aí eu dizia: "minha filha, eu não sou macumbeira, desde os sete anos de idade que eu trabalho e não é com negócio de fazer mal pra ninguém. Eu trabalho é pra curar, é pra unir também as almas que têm desentendido”. Aí, antes de eu sair, assim, com Ashanti, eu era escarrada: meus filhos ia pro colégio, eles dizia alguma coisa, aí as vezes eu ia pra reunião dos meus filhos nos colégio, aí ficava tudo, assim, de receio, né? Ficava tudo me olhando. [...]. Aí depois que eu... que eu comecei a andar mais, aí não sou mais assim vista, né? Aonde vê falam comigo, pegam na minha mão, né? Aí não pararam mais.

De modo geral, essas situações de preconceito e intolerância contra quem se declara como adepto de uma doutrina afro-brasileira foi um analisador possível de ser observado não somente por meio das entrevistas que realizamos, mas também nos momentos em que acompanhamos os atendimentos à comunidade.

Isso ficou bastante evidente quando adentramos o terreiro de Mmaabo, mais especificamente em dois momentos: quando presenciamos, em mais de uma ocasião, uma consulente (Afya) se esconder dentro da residência de Mmaabo com o intuito de não ser reconhecida por alguns amigos, os quais possivelmente não sabiam que a mesma frequentava o terreiro; e na ocasião em que uma mulher (Effiwat), que acompanhava seu pai, afirmou que as pessoas da Umbanda eram esquisitas e estranhas.

No primeiro caso, o processo se desenrolou do seguinte modo: em uma de nossas tardes no referido terreiro, enquanto algumas pessoas esperavam pelos atendimentos da divindade curadora da casa, que percebemos que Afya, consulente bastante assídua do terreiro, estava há mais de uma hora "escondida" dentro da residência de Mmaabo.

Após ser descoberta, ela saiu meio assustada, e olhando para todos os lados antes de efetivamente se juntar a nós no banco de madeira. Segundo os consulentes do recinto, esse comportamento era frequente por parte da distinta mulher, sendo que em momentos anteriores ela já havia passado toda tarde dentro da residência, só saindo ao final da cerimônia para poder ir embora.

Em seguida, Afya concordou com os demais, explicando-nos que assim agia porque nem todo mundo compreendia os motivos de uma pessoa frequentar um terreiro. Os demais consulentes concordaram com a mulher, chegando alguns deles a confessarem que não gostariam de se deparar com pessoas conhecidas frequentando a casa de Mmaabo. 
A outra situação que acompanhamos no mesmo estabelecimento religioso, e que também nos remeteu a esse assunto, aconteceu enquanto conversávamos com algumas consulentes antes dos atendimentos à comunidade. Era véspera do festejo de São Sebastião, de modo que todo o local estava ornamentado com bandeirinhas coloridas. A iminente comemoração era aguardada com alegria e animação entre os adeptos da casa, visto que, juntamente com o culto à divindade, também seria comemorado o aniversário da mãe de santo que conduzia o estabelecimento.

Pois bem, uma das mulheres (Effiwat) atendidas nesse dia se revelou extremamente falante: durante o momento de espera, conversou com muitas pessoas sobre os mais diversos assuntos. Em determinado momento, eis que a distinta figura questiona as pessoas próximas se as bandeirinhas dependuradas no teto eram por causa de alguma festa de São João. Respondendo ao questionamento, uma consulente (Elon), então, explicou sobre o que realmente se tratava.

Em seguida, Effiwat continuou a conversa, relatando já ter frequentado um terreiro de Umbanda em ocasião anterior, contudo, segundo a própria, a experiência não havia sido das mais agradáveis, já que os religiosos do local haviam lhe dado um chá de erva cidreira que não lhe fez bem e terminou ocasionando um desmaio. Elon, aparentemente inconformada com a narrativa, questionou-a sobre o real motivo do mal-estar, já que a substância era ingerida por muitas pessoas e dificilmente provocava tamanhos efeitos.

Depois de refletir alguns instantes, Effiwat, então, deu uma nova explicação para o desmaio: quando estava no terreiro, acabou se deparando com os médiuns e os brincantes de salão, os quais estavam com suas roupas típicas (denominadas por ela como "erradas e estranhas"), realizavam suas danças ritualísticas e incorporavam suas divindades. Por conta do medo, acabou desmaiando e foi embora antes mesmo que a cerimônia tivesse fim.

Assim, ao nos depararmos com essas narrativas de discriminação, preconceito e intolerância contra quem frequenta uma religião de matriz africana, podemos perceber que nossas existências continuamente são expostas a determinados enquadramentos sociais, econômicos e políticos, como é o caso da linguagem, do trabalho e do desejo, os quais tornam possíveis a sobrevivência e a prosperidade dos corpos. Essas normativas, contudo, a depender das condições de existência que estamos falando, não operam através das mesmas lógicas: ao mesmo tempo que existem vidas passíveis de dor e de pesar caso sejam perdidas, outras não são (Butler, 2015).

Entretanto, nem tudo que concerne uma vida é produzido a partir de enquadramentos: algumas existências simplesmente podem ser denominadas como precárias. Por mais que todas as vidas, de certo modo, também assim o sejam, já que, como seres sociais que somos, desde pequenos dependemos dos outros para sobreviver e nos sustentar, acreditamos que esses enquadramentos estruturam os posicionamentos que percebem determinadas vidas como vidas, ao mesmo tempo que outras, apesar de também estarem vivas, não assumem essa condição (Butler, 2015).

Com isso, nossos sentimentos de horror, culpa, sadismo ou indiferença passam a ser seletivos a depender de quais povos estamos falando e das condições em que eles vivem: por um lado, passam a ser justificadas as diferentes formas de violência exercida contra os povos de terreiros, como as que acontecem, conforme pudemos perceber, no âmbito da família, da escola ou da vizinhança, ao mesmo tempo que são lamentados os atendados contra escolas norte-americanas. 
Outro aspecto que também nos auxilia na compreensão dessas cenas de intolerância e descaso aos povos de terreiros diz respeito ao chamado necropoder, termo cunhado com o intuito de designar um processo de criação de uma geografia do terror: através de uma dinâmica de fragmentação territorial e acesso proibido a determinadas zonas, semelhante ao modelo do apartheid há a criação de linhas territoriais provisórias que unem determinadas regiões a outras através de vigilância e controle (Mbembe, 2011).

Nesse contexto, comumente se percebe a adoção de estratégias de ocupação do território inimigo, tais como: destruição de casas, estradas e cidades; roubo da comida; bombardeamento e interferência nas comunicações eletrônicas e nos transformadores elétricos; isolamento das pistas de aeroportos; inutilização de emissoras de rádio e tevê; saqueamento dos símbolos culturais e político-burocráticos do território invadido; dentre outros aspectos (Mbembe, 2011).

O caso mais extremo desse tipo de situação diz respeito à Faixa de Gaza. Contudo, também é possível visualizarmos essa tecnologia de poder em menores graus e proporções, quando, por exemplo, nos deparamos quando praticantes das religiões afro-brasileiras precisam esconder as religiões que professam para que não sofram nenhum tipo de violência.

A partir do elencado até aqui, podemos denunciar uma "explosão nos regimes de visibilidade e dizibilidade em torno dos terreiros": longe de acreditarmos na assertiva de que essas doutrinas são, na realidade, instituições invisíveis ao poder do público e à sociedade de forma geral, partimos da premissa de que não apenas as africanidades, como também toda espécie de vida precária, é constantemente colocada em evidência.

É o que podemos observar nos momentos em que, por exemplo, ligamos a televisão e a sintonizamos em um noticiário que está veiculando a morte de um homossexual, ou caso estejamos em um ônibus e escutemos duas pessoas conversando sobre como os moradores de rua supostamente seriam pessoas "desleixadas". Em todas essas situações, há um interesse sobre essas existências que escapam às normas, não para acolhê-las ou inclui-las, mas para garantir que elas estejam o mais distante possível de onde os normativos se encontram.

Nesse sentido, quem se atreve a vivenciar as religiosidades afro-brasileiras em suas totalidades passa a ser constantemente menosprezado nos mais variados contextos que costuma adentrar, seja ele na família, na escola, no trabalho, no interior da religião e entre os próprios consulentes.

\section{Considerações finais}

A partir dos discursos com que nos deparamos durante nosso mergulho nos terreiros investigados, foi possível perceber que tais doutrinas religiosas têm ocupado, no cenário urbano, zonas historicamente impossibilitadas do acesso à saúde, educação, assistência, segurança, moradia, transporte público de qualidade e infraestrutura urbana, cenários nos quais nossos antepassados escravizados majoritariamente se concentraram após a abolição do trabalho escravo por parte do então império brasileiro. 
É importante, entretanto, ressaltarmos que por mais que tais estabelecimentos sagrados ocupem esses espaços, os praticantes e consulentes que os frequentam costumam habitar os mais distintos pontos da cidade (ou até mesmo fora dela). Essa realidade é completamente distinta dessas doutrinas e crenças no âmbito das ruralidades quilombolas, já que nesses contextos, na maioria das vezes, as africanidades, o companheirismo, as redes de solidariedade e o culto aos Orixás são fortes elementos identitários que caracterizam a comunidade.

Todavia, independentemente de onde estejam inseridos, uma questão que costuma atravessar o cotidiano dos praticantes e consulentes dessas doutrinas religiosas são as situações de discriminação, preconceito e intolerância, seja através de modos extremos, como por meio de queimas de terreiros (como aconteceu em um estabelecimento religioso de matriz africana na cidade em que desenvolvemos nosso estudo), seja através de meios velados e sutis, como por exemplo, olhares e gestos de menosprezo nas situações em que umbandistas utilizam suas roupas típicas em locais públicos.

Tais situações operam no nível do instituído e, na maioria das vezes, produzem reverberações nos modos de ser e de existir dos adeptos e consulentes dessas crenças, produzindo sofrimento entre todos os atores sociais que se encontram envolvidos nessas doutrinas sagradas.

\section{Notas}

1 Os "senhores de engenho" eram os responsáveis pelos engenhos produtores de açúcar durante o período colonial brasileiro. As pessoas interessadas nesse empreendimento recebiam as unidades açucareiras pelos donatários e representantes da coroa portuguesa.

2 Todos os sujeitos a que essa pesquisa fizer referência estão sendo apresentados por nomes fictícios, todos de origem africana.

3 Obedecemos as normas e procedimentos éticos relativos às pesquisas envolvendo seres humanos, em acordo com as resoluções n ${ }^{\circ}$ 466/2012 e n 510/2016, ambas do Conselho Nacional de Saúde (CNS). A investigação também foi submetida ao Comitê de Ética em Pesquisa (CEP), da Universidade Federal do Piauí (UFPI), Campus Ministro Petrônio Portela, e obteve parecer favorável para sua execução sob o CAAE n ${ }^{\circ}$ 79267617.7.0000.5214. 


\section{Referências}

Alves, C. Z. J. \& Paula, C. G. (2014). Espaços luminosos e espaços opacos na metrópole de São Paulo: um estudo de caso da topologia dos bancos de investimento e bancos comunitários. In Anais do VI Congreso Iberoamericano de Estudios Territoriales y Ambientales (pp. 23162337). São Paulo.

Barros, M. (2009). O candomblé bem explicado (Nações Bantu, Iorubá e Fon). Rio de Janeiro: CIP-BRASIL.

Butler, J. (2015). Quadros de guerra: quando a vida é passível de luto? (S. T. N. Lamarão \& A. M. Cunha, Trads.). Rio de Janeiro: Civilização Brasileira.

Campos, I. S. \& Rubert, R. A. (2014). Religiões de matrizes africanas e a intolerância religiosa. Cadernos do LEPAARQ, 11(22), 294-307. Recuperado de

https://periodicos.ufpel.edu.br/ojs2/index.php/lepaarq/article/view/3390/3424 Castillo, L. E. (2017). O terreiro do Gantóis: redes sociais e etnografia histórica no século XIX. Revista de História, 176, 1-57. http://www.scielo.br/pdf/rh/n176/2316-9141-rh-a05616.pdf Castro, Y. P. (2012). O tráfico transatlântico e a distribuição da população negra escravizada no Brasil colônia. Revista Digital Africanias, 2, 1-12. Recuperado de http://www.africaniasc.uneb. br/pdfs/n_2_2012/ac_03 castro.pdf

Foucault, M. (2005). Em defesa da sociedade: curso no Collège de France (1975-1976). São Paulo: Martins Fontes.

Freire, P. (2004). Pedagogia da tolerância. São Paulo: Editora UNESP.

Freitas, M. S. (2012). Refletir sobre a história do negro no Brasil: uma resposta ao racismo. In II Congresso de Educação da UEG (pp. 116-123). Goiás: UEG. Recuperado de http://cdn.ueg.edu.br/arquivos/ipora/conteudoN/975/CE 2012 27.pdf Instituto Brasileiro de Geografia e Estatística [IBGE]. (2010). Parnaíba/Panorama. Recuperado de https://cidades.ibge.gov.br/brasil/pi/parnaiba/pesquisa/23/22107?detalhes=true Lages, S. R. C. (2012). Saúde da população negra: a religiosidade afro-brasileira e a saúde pública. Psicologia Argumento, 30(69), 401-410. Recuperado de

https://periodicos.pucpr.br/index.php/psicologiaargumento/article/view/23295 Lima, V. M. \& Mariano, R. (2008). A relação entre as religiões de matriz africana e o Movimento Negro em Porto Alegre/RS. In III Mostra de Pesquisa de Pós-Graduação da PUCRS (pp. 1-3). Porto Alegre: PUCRS. Recuperado de:

http://www.pucrs.br/edipucrs/online/IIImostra/CienciasSociais/61918\%20-\%20VANESSA\%20MOREIRA\%20DE\%20LIMA.pdf

Lourau, R. (1995) A análise institucional (M. Ferreira, Trad.). Petrópolis, RJ: Vozes.

Lourau, R. (2004). Pequeno manual de análise institucional. In S. Altoé (Org.), René Lourau: analista institucional em tempo integral (pp. 122-127). São Paulo: HUCITEC.

Mbembe, A. (2011). Necropolítica seguido de Sobre el gobierno privado indirecto. Madrid: Melusina.

Miskolci, R. (2003). Reflexões sobre normalidade e desvio social. Estudos de Sociologia, 7(13), 109-126. Recuperado de

https://periodicos.fclar.unesp.br/estudos/article/view/169

Pereira, B. C. S. (2017). Intolerância Religiosa e as Relações Étnico-Raciais: o caso das religiões de matriz africana no Brasil. In VIII Jornada Internacional de Políticas Públicas (pp. 1-10). São Luís: UFMA. Recuperado de: http://www.joinpp.ufma.br/jornadas/joinpp2017/pdfs/ eixo6/intoleranciareligiosaeasrelacoesetnicoraciaisocasodasreligioesdematrizafricananobras. pdf. 
Rocha, J. G. (2011). A intolerância religiosa e religiões de matrizes africanas no Rio de Janeiro. Revista África e Africanidades, 4(14-15), 1-20. Recuperado de http://www.africaeafricanidades.com.br/documentos/14152011-05.pdf.

Sales, R. L. (2014). O terreiro e a cidade: ancestralidade e territorialidade nas políticas de ação afirmativa. Estudos de Sociologia, 2(20), 1-25. Recuperado de https://periodicos.ufpe.br/revistas/revsocio/article/view/235560

Santos, M. (1988). Metamorfoses do espaço habitado: Fundamentos teóricos e metodológicos da geografia. São Paulo: HUCITEC.

Santos, M. (2006). Por uma outra globalização: Do pensamento único à consciência universal (13 ${ }^{\mathrm{a}}$ ed.). Rio de Janeiro: Record.

Santos, M. (2007). Território, Territórios: Ensaios sobre o ordenamento territorial ( $3^{\mathrm{a}}$ ed.). Rio de Janeiro: Lamparina.

Santos, M. (2013). Técnica, Espaço, Tempo: Globalização e meio técnico-científico informacional. São Paulo: EDUSP.

\section{MATHEUS BARBOSA DA ROCHA \\ http://orcid.org/0000-0003-2483-1100}

Docente do corpo provisório do curso de Psicologia da Universidade Federal do Piauí (UFPI)/Campus Ministro Reis Velloso/Parnaíba. É mestre (2018) e graduado (2016) em Psicologia por essa mesma instituição de ensino.

ENDEREÇO: Universidade Federal do Piauí, Campus Ministro Reis Velloso, Departamento de Psicologia. Av. São Sebastião, 2819, Reis Veloso, 64202020 - Parnaíba, PI - Brasil.

E-MAIL: matheusbr.psico@live.com

\section{ANA KALLINY DE SOUSA SEVERO \\ http://orcid.org/0000-0002-9548-6394}

Docente do curso de Psicologia e do Programa de Pós-graduação em Saúde Coletiva da Universidade Federal do Rio Grande do Norte (UFRN)/ Campus de Santa Cruz. É doutora (2014) em Saúde Coletiva pela Universidade Estadual de Campinas (UNICAMP) e graduada (2007) e mestre (2009) em Psicologia pela Universidade Federal do Rio Grande do Norte (UFRN).

E-MAIL: kallinysevero@yahoo.com.br

\section{ANTONNIO VLADIMIR FÉLIX-SILVA \\ http://orcid.org/0000-0003-3084-379X}

Docente do curso de Medicina e do Programa de Pós-graduação em Psicologia da Universidade Federal do Piauí (UFPI)/Campus Ministro Reis Velloso/Parnaíba. Doutor em Ciências Psicológicas pela Universidade de Havana (Cuba).

E-MAIIL: wladyfelix@hotmail.com 
Submissão em: 21/10/2018

Histórico

Revisão em: 20/05/2019

Aceite em: 29/05/2019

Concepção: MBR; AKSS; AVFS.

Coleta de dados: MBR

Análise de dados: MBR; AKSS; AVFS.

Contribuição dos autores $\quad$ Elaboração do manuscrito: MBR; AKSS; AVFS.

Crítico revisões de conteúdo intelectual importante: AKSS; AVFS.

Final aprovação do manuscrito: AKSS; AVFS.

O presente trabalho foi realizado com apoio da Coorde-

Financiamento

Consentimento de uso de imagem

Aprovação, ética e consentimento nação de Aperfeiçoamento de Pessoal de Nível Superior

- Brasil (CAPES) - Código de Financiamento 001.

Foi obtido o consentimento escrito dos participantes e/ ou do detentor dos direitos autorais sobre a imagem.

A investigação foi submetida ao Comitê de Ética em Pesquisa (CEP), da Universidade Federal do Piauí (UFPI), Campus Ministro Petrônio Portela, e obteve parecer favorável para sua execução sob o CAAE $\mathrm{n}^{\circ}$ 79267617.7 .0000 .5214$. 